\title{
Reliability analysis of library and media teachers' performance improvement
}

\author{
Hasnah Shuhaimi 1, *, Norasiah Harun ${ }^{1}$, Saidatul Akmar Ismail ${ }^{1}$, Saiful Farik Mat Yatin ${ }^{1}$, Aszunarni Ayob ${ }^{2}$ \\ ${ }^{1}$ Faculty of Information Management, Universiti Teknologi MARA, Puncak Perdana Campus, Shah Alam, Selangor, Malaysia \\ ${ }^{2}$ Faculty of Education, Universiti Kebangsaan Malaysia, Bangi, Selangor, Malaysia
}

\section{A R T I C L E I N F O}

\section{Article history:}

Received 5 November 2016

Received in revised form

4 January 2017

Accepted 7 January 2017

\section{Keywords:}

Performance improvement skills

Motivation

Knowledge

LMTs perception

\begin{abstract}
A B S T R A C T
This paper reports reliability analysis from the pilot study on factors affecting Library and Media Teachers (LMTs) Performance Improvement. Thirty-eight respondents involved were from the Teachers' Activities Centre (TAC) of Kapar and Telok Gadong Zone, Klang, Selangor. Respondents responded to all 153 questions on the Factors Affecting LMTs Performance Improvement (Skills and Knowledge) with motivation as the moderating factors (Commitment, Self-Efficacy, Reward, Task Complexity, Feedback) and LMTs Perception on two SRCM Courses (Basic and Intermediate) and also LMTs Performance Improvement. The 153 questions included nine questions on profiles background. The overall Cronbach's Alpha reliability on the items is 0.995 , indicating that the measurement reflected high reliability. This study is specifically on research about factors (skills, knowledge, LMTs perception through Basic $(35 \mathrm{H})$ and Intermediate $(45 \mathrm{H})$ SRCM Courses), motivation as the moderator factors that affecting LMTs performance improvement. In this study, researchers used the stratified sampling method; 16 states in Malaysia as a stratum. The total population is 2392 LMTs in Malaysian secondary schools. The findings of this study will offer helpful information to the educational planners, and the suggestions and recommendations based on this study will be helpful for the general betterment of the effectiveness of the training through LMTs perception, skills, knowledge and motivation that significant effects to LMTs performance improvement. The final outcome from this research is to propose a framework that integrates the SRC and LMTs performance improvement based on research findings.

(C) 2017 The Authors. Published by IASE. This is an open access article under the CC BY-NC-ND license (http://creativecommons.org/licenses/by-nc-nd/4.0/).
\end{abstract}

\section{Introduction}

The School Resource Centre (SRC) is well known as the hub of access information includes numerous printed, non-printed, digital sources and managed systematically in order to expand teaching and learning value. In Malaysian context, the Educational Technology Division (ETD) is responsible on the SRC growth. SRC is managing by Library and Media Teacher (LMT) who are in control to maintaining, acquiring and processing of educational resources via services (Fadzliaton and Kamaruzaman, 2010). Kamal and Normah (2012) highlighted that the LMT has to ensure that SRC's collection supports the most

\footnotetext{
* Corresponding Author.

Email Address: hasnahshuhaimi@gmail.com (H. Shuhaimi) https://doi.org/10.21833/ijaas.2017.03.005

2313-626X/@ 2017 The Authors. Published by IASE.

This is an open access article under the CC BY-NC-ND license (http://creativecommons.org/licenses/by-nc-nd/4.0/)
}

recent standards of educational sources and manages efficiently and effectively educational materials via services.

The researchers believe that LMTs should play active part within school community and helps to improve the quality of teaching and learning. LMTs are important assets that help the SRC to execute and achieve Education Philosophy parallel with SRC Philosophy productively. They are the basis of getting the work completed effectively and efficiently, and the source of innovation and creativity. In order for SRC to accomplish its objectives and goals, it needs to consider the important role of LMTs. LMTs require a highly competent, skilled and trained workforce. Moreover, to uphold a skilful advantage, LMTs must actively be trained and build up. In this study, researchers used the stratified sampling method; researchers make use of 16 states in Malaysia as a stratum. The total population is 2392 LMTs in secondary schools. 


\subsection{Challenges in LMTs performance improvement}

Since 1945, the American Association of School Librarians (AASL) has established the important role of LMTs. As refer to AASL and AECT in 1998, there are four categories of roles and responsibilities in the description of the LMT: teacher, instructional partner, information specialist and program administrator. Within those four categories, the LMT is viewed as a problem solver, book recommender, collaborator, trainer and clerk. Shannon (2002) claimed that LMT should lead the learning environment through curriculum design, instruction and technology while collaborating with "all members of the learning community to create a student-center library media program". Diversity of LMTs responsibilities challenges them to improve their performance to become well trained and knowledgeable.

In Malaysian context, the government spends billions of ringgit to expand human capital quality for the nation, especially in the education sector. The education sector received an allocation of a sum of MYR 54, $600,593,800.00$ billion or $21 \%$ of the total allocation in the 2013-2014 Budget (MOF, 2014). Despite of a government attempt to improve teachers' performance, including the LMTs, a few literatures related to school resource centre management in Malaysia has established that the LMTs have lack adequate skills to manage SRCs. Several studies revealed that LMTs lack of ICT skills, communication, team work and leadership skills (Abdullah and Singh, 2000; Raja and Saidina, 2003; Abdullah and Zainab, 2008; Tan et al., 2012). A research done by Kamal and Normah (2012) has revealed that although generally LMTs do have the fundamental knowledge to manage SRCs, but still inadequate for them to handle the library effectively and efficiently. Similarly, Nor (2014) in paperwork presented to Education of Technology Division (ETD) affirmed that there has been a frequent changed of LMTs due to incompetency. Furthermore, he concluded that the factors contributing the problems because LMTs lack of knowledge in terms of information literacy, SRC resources, and SRC management. This scenario causes ineffective management and less so on the SRC services, reading activities, library promotion and information literacy program.

Prior studies showed that methods to training were frequently conducted informally and unsystematically with most stakeholders relying heavily on upper management judgments to create training judgment such as types of training and which person to obtain training (Smith et al., 1997; Rae and Carswell, 2001; Rothwell, 2008). Evidence along with showed that SRCM Courses conducted (Basic $35 \mathrm{H}$ and Advanced $45 \mathrm{H}$ ) for LMTs was occasionally not significant, as contributed to the largely important objectives of the SRC (Carliner, 2003). Numerous of studies in Malaysian context found that the existing SRCM Courses is an unsatisfactory (Raja and Saidina, 2003; Kamal and Normah, 2012; Tan, 2014). The researchers revealed that the quality of training (SRCM Courses) did not assemble the LMTs expectations and needs, and programs were carried out briefly giving insufficient time for the LMTs to engross themselves in the training subjects. Similarly, Tan (2014) also claimed that training (SRCM Courses) was imperfect and lacked quality. Hence, she emphasized the need for further research on the problems in training, and improving performance. Likewise, the previous findings (Tan et al., 2012) claimed that the LMTs themselves had low motivation in their work and professional development programs. Low motivation causes of LMTs low commitment and low selfefficacy in their professional work. Prior studies agreed that having low level of self-efficacy may lead to weaken task complexity in challenging activities (Weiner, 1980). Research done by Tan (2014) also revealed that school management lack in benevolent reward and good feedback on the task given. In line, LMTs also did not understand well their task and duties as LMTs. It also decreases their motivation in managing SRC efficiently and effectively. Researchers believe that if school management play more effective role as the pace setter and facilitator for LMTs performance improvement, LMTs motivation will be increase (Tan, 2014; Kamal and Normah, 2012). To obtain more insight about the LMTs performance improvement, the researchers has done a preliminary interview and found a few issues in the training were conducted by the Educational Technology Division (ETD). Through the researcher's personal communication with three persons in charge of SRC training programs, they are one of ETD's official and two of the library educators. The ETD officer has noted many imperfections in training for LMTs. He said that the ETD had unsatisfactory information to scrutinize the training needs that can improve LMTs performance. On the other hand, two officials who were library educators for more than ten years agreed that LMTs perceptions on existing training are crucial needed to enhance their performance. Studies done by Tan (2014) and Kamal and Normah (2012) have confirmed the problem arise in training for LMTs.

By reason of the lack of particular analysis and study on the LMTs performance improvement, and the prolonged issues of LMTs lack of knowledge, skills and expertise to manage effectively and efficiently of SRC and its related activities. This study is an attempt to take up the fundamental layer of LMTs performance improvement. Therefore, this study to investigating factors affecting LMTs performance improvement is deemed important in order to rectify the issues of LMTs performance in Malaysia. The researcher strongly feels that it is timely to conduct this research to consolidate factors affecting LMTs performance. The findings of this study will provide useful information to the educational planners, and the suggestions and recommendations based on this study will be helpful for the general betterment of the effectiveness of the 
training through LMTs perception, skills, knowledge and motivation that significant effects to LMTs performance improvement.

\subsection{Sampling method}

In the stratified sampling method, researchers used 16 states in Malaysia as a stratum. The total population is 2392 LMTs in Malaysian secondary schools. The list of secondary schools in Malaysia for every state is obtained from the Ministry of Education 2015 website. The number of respondent, $\mathrm{n}_{\mathrm{h}}$ for each stratum is calculated based on the number of school in each stratum, $\mathrm{N}_{\mathrm{h}}$ as well as estimator formula are attached. After that, simple random sampling technique is used to choose the respondent from each stratum. The random sample is computed using Excel software by assigning each row of data a random number and use sorting to pick the sample for each stratum. For example 34 out of 246 schools in Perak are randomly selected using Excel in order to have the sample size for that particular state (Table 1).

Table 1: Allocation of sample size

\begin{tabular}{|c|c|c|c|c|}
\hline No. & State & Total of Lmts & Sample Size Calculation & Sample Size \\
\hline 1 & Perak & 246 & $\frac{246}{2392} \times 332=34.14$ & 34 \\
\hline 2 & Selangor & 275 & $\frac{275}{2392} \times 332=38.11$ & 38 \\
\hline 3 & Pahang & 192 & $\frac{192}{2392} \times 332=26.65$ & 27 \\
\hline 4 & Kelantan & 173 & $\frac{170}{2392} \times 332=24.011$ & 24 \\
\hline 5 & Sabah & 219 & $\frac{219}{2392} \times 332=30.59$ & 30 \\
\hline 6 & Johor & 274 & $\frac{274}{2392} \times 332=38.03$ & 38 \\
\hline 7 & Kedah & 200 & $\frac{200}{2392} \times 332=27.76$ & 28 \\
\hline 8 & WP Putrajaya & 11 & - & 5 \\
\hline 9 & Melaka & 77 & $\frac{11}{2392} \times 332=10.69$ & 11 \\
\hline 10 & Negeri Sembilan & 123 & $\frac{123}{2392} \times 332=17.07$ & 17 \\
\hline 11 & Pulau Pinang & 127 & $\frac{121}{2392} \times 332=17.63$ & 18 \\
\hline 12 & Perlis & 30 & $\frac{30}{2392} \times 332=4.16$ & 4 \\
\hline 13 & Sarawak & 187 & $\frac{1392}{239} \times 332=25.95$ & 26 \\
\hline 14 & Terengganu & 147 & $\frac{1 \mathrm{TH}}{2392} \times 332=20.41$ & 20 \\
\hline 15 & WP Kuala Lumpur & 101 & $\frac{101}{2392} \times 332=14.02$ & 14 \\
\hline \multirow[t]{2}{*}{16} & WP Labuan & 10 & - & 5 \\
\hline & & 2392 & 332 & 339 \\
\hline
\end{tabular}

\subsubsection{Sample size}

Determining sample size is a very important issue because samples that are too large may waste time, resources and money while samples that are too small may lead to inaccurate results. The aim of the calculation is to establish sufficient sample size to estimate the population prevalence with fine precision (Naing et al., 2006). The common sample size calculation is:

$n=\frac{z_{\alpha / 2}^{2} S^{2}}{e^{2}+\frac{z_{\alpha / 2}^{2} S^{2}}{N}}$

This study used $\alpha=0.05$ that is the $95 \%$ confidence level and $e=0.15$, which is the margin of error. Since, the variance of the population is unknown, $p(1-p)$ will be used instead of $S^{2}$ where $p=0.5$. Hence, the sample size for the population is:

$n=\frac{1.96^{2}(0.5)(1-0.5)}{0.05^{2}+\frac{1.96^{2}(0.5)(1-0.5)}{2392}}=331.006 \approx 332$

\section{Pre test}

The questionnaire was adopted, adapted and constructed from previous studies (Tan, 2014; Khatri and Gudadhe, 2013; Bekele et al., 2014; Shahzadi et al., 2014; Rakiro, 2013; NCDPI, 2015). Subsequently, the researchers gave out the instrument to a set of LMTs to come across their general opinions. They reviewed the questionnaire designs, wording of the questions and instructions in an informal setting. The researchers had done the pre-test to LMTs from Sekolah Menengah Kebangsaan Perempuan Kapar, Sekolah Menengah Kebangsaan Meru and Kolej Islam Sultan Alam Shah. These three schools located in Klang, Selangor. They have more than 10 years' experience as LMTs. Gay et al. (2009) considers that three to four individuals who are thoughtful, critical and similar to the proposed respondents would be sufficient to help recognize problems. Moreover, respondents of pretest are ideally as they resembled the survey's target population (Converse and Presser, 1986). They answered and made several beneficial comments 
about the questionnaire. This was to ensure the group understood the meaning of the questions and provided adequate variation of answers (Bethlehem, 2009). Their advice and comments were taken into deliberation. The researchers amended a few question structures, question approaches and altered the answers provided. Their evaluation are useful in identifying questionnaire inaccuracy including typographical errors, complex layout and instructions, the flow and coherency of questions as suggested by Biemer and Lyberg (2003).

\section{Validity}

In the process of producing a sound and quality research, the designed instrument has gone through a handful of processes to ensure that conclusions and implications based on the data collected were valid and reliable as suggested by Fraenkel et al. (2011). They explained that validity refers to which evidence is supported by any inferences made by the researcher based on the collected data using the instrument. These inferences should be appropriate, meaningful, correct and useful as it validates the research and not the instrument itself. For further validation, the content validity is taken into consideration to ensure that the contents of the questionnaire matched intended contents. Several scholars highlight that the experts' judgement helps to scrutinize the instrument to ascertain its validity for measuring the characteristics in question (Leedy and Ormrod, 2005; Neuman, 2006; 2009; Salkind, 2006; Fraenkel et al., 2011; Bryman, 2012). According to Gay et al. (2009), there is no formula or statistic that can be computed or any other way to express it quantitatively. Thus, expert judgement is the only practicable way to assess content validity with numerous revisions and improvements (Vogt, 2007). The researchers noted the comments and corrected the instrument.

Next, the researchers handed over the instrument to two of English and Malay Teacher who are experts in linguistics; and also LMTs experts from Selangor State Education Technology Department (SETD) for reviews and validations. They are the Director and
Deputy Director of Selangor State Education Technology Department and Selangor Senior School Resource Centre (SRC) Trainers. They assessed, reviewed, and determined its sufficient contents and validity. The researcher noted their feedbacks and comments along amendments and improves the instrument as suggested.

\section{Pilot test}

As soon as the instrument was pre-tested and validated, the researcher carried out the pilot test. The respondents of the pilot test were the LMTs in secondary schools as they are the intended samples in the specific research. Thirty-eight LMTs did the pilot test. They were from the Klang district of Selangor. The instruments were distributed through two Teachers' Activities Centre (TAC) of Kapar and Telok Gadong Zone. Muijs (2004) and Redline et al. (2005) established that piloting the instrument with the targeted samples is to solicit LMTs opinions on the instruments as well as the research as a whole.

\section{Reliability analysis}

In the process of developing a consistent and dependable research instrument, the instrument was tested so that the measurements between the respondents were not too varied across time periods and that a measurement taken at any point in time was reliable (Cohen et al., 2007; Hair et al., 2010; Neuman, 2006). The pilot test data were analysed using the IBM SPSS Statistics 20.

Thirty-eight respondents answered all the 141 questions on the Factors Affecting LMTs Performance Improvement (Skills and Knowledge), with motivation as moderating factors (Commitment, Self-Efficacy, Reward, Task Complexity, Feedback) and LMTs Perception on two SRCM Courses (Basic and Intermediate) and also LMTs Performance Improvement. The 153 questions included nine questions on profiles background. Table 2 shows the results of LMTs Profiles Background.

Table 2: Descriptive analysis for profiles background

\begin{tabular}{cccc}
\hline Constructs & Operational & Frequency & Percentage (\%) \\
\hline & Urban Area & 17 & 44.7 \\
Location & Rural Area & 21 & 55.3 \\
& & & 100 \\
& 24 H Electricity & 38 & 94.7 \\
Facilities & Computer & 36 & 89.5 \\
& Internet & 34 & 13.2 \\
Qualifications in Library and Information & & 5 & 2.6 \\
Science/Educational Technology & One Year SRCM Course & 1 & 7.9 \\
& 14 Weeks SRCM Course & 3 & 13.2 \\
& Diploma & 5 & 2.6 \\
\hline
\end{tabular}

\subsection{Personal profile of respondents}

For general information, one LMT is equivalent to one school. There are nine questions under profiles background. Out of 38 respondents, $44.7 \%$ of respondents were from urban area, while the rest were from rural area. Fortunately, 38 of the schools had good infrastructure facilities. There were 100\% 
schools with 24 hours electricity supply. A total of $94.7 \%$ schools had computer facilities and another 89.5\% schools have internet facilities. The numbers of LMTs attending courses such as In-service SRCM 14 weeks was lower and as for courses of one year, only $15.8 \%$ have attended. Most LMTs hold minimum Library and Information Science (LIS) qualifications. Overall, it can be summarized into 5 levels of qualifications.

\subsection{Cronbach's alpha results}

As shown in Table 3, there are thirty three items under Skills factors. Among Skill factors, Leadership holds the highest result, which is 0.951 , followed by Communication 0.915, Teamwork 0.866 and ICT 0.814. The overall Cronbach's Alpha reliability on the Skills is 0.886. All Knowledge factors in the other hand holds 0.9 Cronbach's Alpha Reliability. Information Literacy is 0.974 , followed by SRC Management 0.931 and SRC resources 0.910 . The overall Cronbach's Alpha Reliability on Knowledge factors is 0.938 . There are twenty six items under Knowledge factors.

Furthermore, there are thirty items under Motivation factors. One of motivation factors have shown under 0.9 reliability results, which is Task Complexity 0.867 . The highest results hold by Commitment $=0.982$, followed by Self-Efficacy $=$ 0.980 , Reward $=0.941$ and Feedback $=0.931$. The overall Cronbach's Alpha Reliability on Motivation factors is 0.940 . There are forty five items under LMTs Perception. Basic SRCM result is 0.961, followed by Intermediate SRCM $=0.984$, Content Basic SRCM $=0.987$ and Content Intermediate SRCM $=0.984$. Last but not least is Library and Media Teachers Performance Improvement $=0.970$. There are ten items under this factor. The overall Cronbach's Alpha Reliability on all items is 0.995, indicating that the measurement reflected high reliability (Field, 2005; Gay et al., 2009; Radhakhrishna, 2007; Vogt, 2007).

Table 3: Cronbach's alpha of each section of the questionnaire

\begin{tabular}{cccc}
\hline Constructs & Operational & Items (N) & Cronbach' Alpha \\
\hline \multirow{3}{*}{ Skills } & ICT & 7 & 0.814 \\
& Teamwork & 6 & 0.866 \\
& Communication & 7 & 0.915 \\
Knowledge & Leadership & 13 & 0.951 \\
& Information Literacy & 11 & 0.974 \\
& SRC Resources & 8 & 0.910 \\
Motivation & SRC Management & 7 & 0.931 \\
& Commitment & 7 & 0.982 \\
& Self-Efficacy & 7 & 0.980 \\
& Task Complexity & 4 & 0.867 \\
& Reward & 7 & 0.941 \\
LMTs Perception & Feedback & 5 & 0.931 \\
& Basic SRCM & 12 & 0.961 \\
& Intermediate SRCM & 13 & 0.984 \\
\end{tabular}

\section{Conclusion}

To sum up, the pilot study was done at two Teachers' Activities Centre in two different dates however in the same month. Overall, the pilot study was successfully managed by the researchers; no questions being asked except several LMTs were unclear about the understanding of SRC management when it comes to Reward questions. The researchers briefly explained to them in the pilot study process. Based on their suggestions, the researcher will include SRC top management to differ from SRC management in the actual questionnaire to avoid misunderstandings among respondents. Finally, once the instrument is ready, the researcher has applied for approval from the Education Planning and Research Development Division (EPRD), MoE to carry out the research in the intended schools. With the endorsement letter, the researcher again wrote and applied for a consent letter to carry out the survey in schools at all sixteen State Education Departments. In the meantime, the researchers are transferring printed questions into online survey using surveymonkey.com to carry out the research.

\section{Acknowledgment}

The authors are grateful to Ministry of Education and Faculty of Information Management, Universiti Teknologi MARA (UiTM) for providing the facilities and funding to carry out the research.

\section{References}

Abdullah A and Singh D (2000). Competencies for teacherlibrarians: The Malaysian perspective. In: Howe E (Eds.), Information Literacy: Key to the future. Papers presented at the $29^{\text {th }}$ Annual Conference of the International Association of School Librarianship (IASL): 77-88. Seattle, USA.

Abdullah A and Zainab AN (2008). The digital library as an enterprise: the Zachman approach. The Electronic Library, 26(4): 446-467.

Bekele AZ, Shigutu AD, and Tensay AT (2014). The effect of employees' perception of performance appraisal on their work outcomes. International Journal of Management and commerce Innovations, 2(1): 138-173. 
Bethlehem J (2009). Applied survey methods: A statistical perspective. John Wiley and Son, New Jersey, USA.

Biemer PP and Lyberg LE (2003). Introduction to survey quality. John Wiley and Son, New Jersey, USA.

Bryman A (2012). Social research methods. Oxford University Press, New York, USA.

Carliner S (2003). Characteristic-based, task-based, and resultsbased: Three value systems for assessing professionally produced technical communication products. Technical Communication Quarterly, 12(1): 83-100.

Cohen L, Manion L, and Morrison K (2007). Research method in education. Routledge, New York, USA.

Converse JM and Presser S (1986). Survey questions: Handcrafting the standardized questionnaire. SAGE Publications, Iowa, USA.

Fadzliaton Z and Kamarulzaman I (2010). Measuring Malaysia school resource centers standards through IQ-PSS: An online management information system. In the $39^{\text {th }}$ International Association of School Librarianship Annual Conference, Brisbane, Australia: 1-20.

Field A (2005). Discovering statistics using SPSS: (and sex and drugs and rock ' $n$ ' roll). SAGE Publications, London, UK.

Fraenkel J, Wallen N, and Hyun H (2011). How to design and evaluate research in education. McGraw-Hill Education, New York, USA.

Gay LR, Mills GE, and Airasian P (2009). Educational research: Competencies for analysis and applications. Pearson Education Ltd, London, UK.

Hair JF, Black WC, Babin BJ, and Anderson RE (2010). Multivariate data analysis. Prentice Hall, New Jersey, USA.

Kamal MA and Normah $O$ (2012). The role of library and media teachers in Malaysian school resource centre. Journal of Education and Practice, 3(15): 120-126.

Khatri AB and Gudadhe VP (2013). Use and user perception of Eresources in SRC Ayurvedic Mahavidyalaya, Chikhli: A study. International Journal of Digital Library Services, 3(4): 47-58.

Leedy PD and Ormrod JE (2005). Practical research: Planning and design. Pearson Education, New Jersey, USA.

Ministry of Finance (MOF) (2014). Malaysians 2014 national budget. MOF, Kuala Lumpur, Malaysia.

Muijs D (2004). Doing quantitative research in education with SPSS. SAGE Publications Ltd., London, UK.

Naing L, Winn T, and Rusli BN (2006). Sample size calculator for prevalence studies. Available online at: http://www.kck.usm.my/ppsg/stats_resources.m

NC Department of Public Instruction (NCDPI) (2015). North Carolina School library media coordinator evaluation process. Available online at: http://ncees.ncdpi.wikispaces.net/file/ view/2015_NC+SLMC.pdf

Neuman LW (2006). Social research methods: Qualitative and quantitative approaches. Pearson Education, Boston, USA.
Neuman LW (2009). Understanding research. Pearson Education, Boston, USA.

Nor AK (2014). Kertas kerja peningkatan profesionalisme guru perpustakaan dan media. BTPN, Selangor, Malaysia.

Radhakhrishna RB (2007). Tips for developing and testing questionnaires/instruments. Journal of Extention, 45(1): 1-4.

Rae D and Carswell M (2001). Towards a conceptual understanding of entrepreneurial learning. Journal of Small Business and Enterprise Development, 8(2): 150-158.

Raja A and Saidina 0 (2003). The training of teacher librarians in comparison with professional librarians in Malaysia. Malaysian Journal of Library and Information Science, 8(2): 27-41.

Rakiro LA (2013). Effects of institutional teacher reward systems on students' performance in kenya certificate of secondary education in Rongo District, Kenya. Ph.D. Dissertation, University of Nairobi, Kenya.

Redline CD, Dillman AD, and Carley-Baxter L (2005). Factors that influence reading and comprehension in self-administer questionnaires. Allgemeines Statistisches Archiv, 89(1): 2138.

Rothwell WJ (2008). Adult learning basics. American Society for Training and Development Press, Massachusetts, USA.

Salkind NJ (2006). Exploring research. Pearson Education International, New Jersey, USA.

Shahzadi I, Javed A, Pirzada S, Nasreen S, and Khanam F (2014). Impact of employee motivation on employee performance. European Journal of Business and Management, 6(23): 159166.

Shannon D (2002). The education and competencies of school library media specialists: A review of the literature. School Library Media Research, 5. Available online at: http://www.ala.org/ala/mgrps/divs/aasl/aaslpubsandjourna ls/slmrb/schoollibrary.cfm

Smith EM, Ford JK and Kozlowski SW (1997). Building adaptive expertise: Implications for training design strategies. In: Quiñones MA and Ehrenstein A (Eds.), Training for a Rapidly Changing Workplace: Applications of Psychological Research: 89-118. American Psychological Association, Washington DC, USA.

Tan SM (2014). School librarians' readiness for information literacy implementation in secondary schools. Ph.D. Dissertation, Universiti Malaya, Kuala Lumpur.

Tan SM, Gorman G, and Singh D (2012). Information literacy competencies among school librarians in Malaysia. LIBRI: International Journal of Libraries and Information Services, 62(1): 98-107.

Vogt PW (2007). Quantitative research methods for professionals. Allyn and Baco, Boston, USA.

Weiner B (1980). A cognitive (attribution)-emotion-action model of motivated behavior: An analysis of judgments of helpgiving. Journal of Personality and Social Psychology, 39(2): 186-200. 